\title{
AS PORNIFICAÇÕES DE SI EM DIÁRIO DA PUTARIA
}

\author{
Mariana Baltar ${ }^{1}$ \\ Nayara Barreto ${ }^{2}$
}

\begin{abstract}
Resumo: Este artigo reflete sobre imagens dos corpos femininos que povoam as múltiplas telas online dentro do contexto contemporâneo da pornografia, argumentando que tais imagens mobilizam novas construções discursivas sobre sexualidade e prazer. Nesse sentido, analisamos o site brasileiro "Diário da Putaria" com o intuito de investigar aspectos especificos da chamada netporn, sua dimensão política, imagética e cultural. A partir dessa investigação, propomos pensar as interconexões entre a pornografia amadora e o que algumas pensadoras da área têm refletido como "pornificação de si". Portanto, propomos problematizar e compreender os embates presentes nessas imagens e, com isso, investigar questões referentes à lógica de produção e consumo de imagens pornográficas a partir das articulações das ideias de pornificação de si, empoderamento e prazer.
\end{abstract}

Palavra-chave: Pornografia. Pornificação de si. Gênero. Amador. Web 2.0.

"Atenção! Divirtam-se com NOSSAS AMADORAS e CASEIRAS e UM SALVE À PUTARIA!", lê-se na página inicial do site Diário da Putaria. As palavras colocam em cena o que é cada vez mais a dinâmica central da pornografia contemporânea: conteúdos gerados pelos usuários na Web, mobilizando, enquanto estética e dispositivo, o espectro do que é genericamente denominado pornô amador.

Mas nessas palavras iniciais, e por todo o site, um outro aspecto se destaca: a dimensão celebratória da putaria. O termo, que no senso comum é carregado de uma condenação moralista, aqui é valorizado como trocas sensoriais e espetaculares entre corpos de homens e mulheres comuns e anônimos que a cada postagem dedicam um especial empenho para tornar a experiência de quem visita a página o mais real, excitante e "amadora" possível.

A partir de um olhar sobre o site pornográfico brasileiro "Diário da Putaria", , este artigo ${ }^{4}$ investiga alguns aspectos específicos da chamada netporn e propõe pensar as interconexões entre a pornografia amadora e o que algumas teóricas tem refletido como pornificação de si (BALTAR, 2013). Propomos lançar um olhar para questões que relacionam a lógica de produção e consumo de imagens pornográficas a partir das articulações das ideias de pornificação de si, empoderamento, prazer e consumo. Neste sentido, reconhecemos esta face contemporânea da pornografia como um produto da cultura da mídia que estabelece novas construções discursivas que conformam identidades, performances de si e práticas de consumo ligadas às sexualidades, como indica Feona Atwood (2006) ao analisar o que define como "nova cultura do sexo".

\footnotetext{
${ }^{1}$ Professora da graduação em Estudos de Mídia e do Programa de Pós-graduação em Comunicação da Universidade Federal Fluminense. E-mail: marianabaltar@gmail.com

2 Doutoranda em Comunicação e Cultura pela Universidade Federal do Rio de Janeiro. E-mail: nayara.matos@gmail.com.

${ }^{3}$ www.diariodaputaria.com

${ }^{4}$ Uma primeira versão desse artigo foi apresentada pelas autoras no MAGIS International Film Studies Spring School, na sessão Porn Studies, em Gorizia, Itália em 2013, sob o título "Inside sex diaries: putaria, identity and ordinary amateur sex."
} 
Nossa proposição é investigar como se dá a construção narrativa das imagens postadas no site, de que forma os elementos estéticos do quadro são articulados, construindo assim, sua estética e seus prazeres. Para tanto, procederemos a uma leitura e análise da composição das imagens, dos elementos constitutivos do quadro e também lançaremos um olhar mais atento para o papel dos comentários para essa construção na narrativa visual de cada postagem.

Devido a uma diversidade de mídias, meios de produções e experiências de visualidade a subjetivação, a pornografia se torna atualmente um domínio amplo. Com mais ou com menos rigor teórico e político, termos e expressões como "pornificação" e "sexualização da cultura" estão sendo usados para enfatizar que a definição comum de pornografia, como algo estritamente relacionado com sexo explícito para estimular o prazer (e levar ao orgasmo), já não dá conta das multiplicidades de narrativas, discursos e práticas de espectatorialidade e consumo que circulam sob o termo, e o peso, do pornográfico. Se de um lado, o pornográfico é um campo expandido - e cada vez mais publicamente aceito em certas arenas socioculturais -, por outro, em muitas das vezes, definir algo como pornografia ainda é, de alguma forma, problemático e pejorativo.

No sentido de evitar tal aura pejorativa, os estudos mais recentes voltados para pornografia focam em exemplos alternativos e ligados a uma vanguarda transgressora que traz consigo uma agenda política específica de resistência e assim tendem a alijar a pornografia mainstream no cerne das discussões. Como Mark Jancovich (2001) argumenta, com esta tendência de deixar de lado a pornografia mainstream, constrói-se a ideia de que na pornografia clássica e heteronormativa nada de muito interessante há para ser investigado, pois nela nada acontece. Por isso, ao escolher o objeto "Diário da Putaria" colocamos nosso olhar exatamente no limiar e no questionamento desse universo onde nada parece acontecer, mas onde na verdade tudo acontece.

Nossa análise e discussões são guiadas por algumas categorias-chave essenciais com certa ressonância no debate teórico do campo de estudos da pornografia: o amador, o consentimento nas imagens, a pornificação de si e a reconfiguração dos espaços e dinâmicas de consumo da pornografia (sobretudo em direção a uma privatização destes). Um dos elementos-chave que queremos apontar é a ideia de que o prazer contido na construção narrativa das imagens é intensificado pela pornificação de si, sendo esta (mobilizada em especial pela relação sujeito - câmera - espectador) o indicativo primordial do consentimento e compartilhamento. Nesse sentido, propomos pensar uma construção narrativa do consentimento que se materializa nas imagens e que de certo modo autoriza seu consumo no site.

Tal construção narrativa do consentimento se expressa enquanto pornificação de si e, argumentamos, catalisa o prazer compartilhado entre imagem-espectador. Claro que esta construção narrativa do consentimento não garante que a divulgação pública das imagens seja também consensual - todo o universo criminoso da chamada revenge porn está aí aberta a reflexões de ordem ético-políticas -, mas, nesse sentido, Diário da Putaria é adamante em cuidar para que todas as imagens divulgadas sejam consensuais nos dois sentidos: na produção e na circulação pública. Ao acessar o site, o usuário/espectador é constantemente alertado, em intensas letras vermelhas: "Atenção: Essas são fotos enviadas ao site de forma eletrônica, tornando impossível a verificação 
da propriedade das mesmas. Caso exista uma foto sua publicada contra a sua vontade, por favor, envie um e-mail para diariodaputaria@gmail.com que imediatamente as mesmas serão retiradas do site." E efetivamente, em algumas ocasiões, nos deparamos com postagens retiradas.

Este cuidado, apresentado também em outros portais - como o PornHub que além da habitual política e termos para o usuário que condena e proíbe a divulgação de conteúdo ilegal (especialmente pornografia infantil, maus-tratos com animais, estupro e postagens de práticas e/ou com divulgação não consentidas), tem um sistema de verificação e autentificação do usuário que posta os vídeos -, de certo modo constrói uma ordem discursiva de legitimidade para o site.

Analisando os blogs que se centram no feminino e seus desejos sexuais (como o blog Imelda Imelda), Julie Bradford (2010) salientou o papel central da autopornificação como forma de empoderar-se do próprio prazer. Desenvolvendo esta questão, Baltar (2013) afirma que a pornificação de si é mais do que apenas se apresentar para o olhar da câmera em conteúdos compartilhados pela internet; é um sintoma geral de um contexto histórico que mobiliza a ideia de que dar-se a ver ao olhar público alheio é um desejo, um direito e uma fonte de prazer. Tal sintoma, enquanto efeito e instrumento de uma subjetividade alterdirigida, está presente de modo ambivalente tanto no vasto mundo amador quanto em projetos mais explicitamente vinculados ao ativismo político tais como o PorNo PorSi, analisado por Baltar no artigo de 2013.

É essa natureza que envolve a relação complexa entre pornografia, consumo, performances amadoras e prazer que queremos discutir a partir das análises das imagens que circulam a partir do site "Diário da Putaria" endossadas pela pornificacação de si.

\section{PORNIFICAÇÃO DE SI E IMAGENS DO FEMININO}

O contexto mais amplo da hipermodernidade no contemporâneo assiste atualmente à "mercantilização quase geral das formas de vida" (LIPOVESTKY, 2004, p. 53). Tal cenário apresenta imagens de temas comuns como mais do que as expressões da vida cotidiana, mas como uma estética e um dispositivo para compartilhamento e disputa de visibilidades. É a partir de tal premissa que refletiremos sobre questões relacionadas às construções das pornificações de si de mulheres anônimas, comuns e reais no site "Diário da Putaria".

Diário da Putaria é apresentado como um diário, onde todos os dias alguém posta um auto-retrato (fotos ou vídeos). Tais postagens diárias ressoam um número de comentários que muito frequentemente levam à troca de contatos pessoais para que seja possível algum tipo de encontro na "vida offline" ou algum tipo de troca comercial e simbólica.

A maioria das imagens são de mulheres que constroem suas auto-imagens emulando as performances de estrelas pornô, numa ansiosa busca por se expor de forma sexy, desejável, incitando o prazer dos olhares alheios. No entanto, seus corpos estão longe dos estereótipos da artificialidade das estrelas pornôs atuantes na pornografia 
mainstream. O site não traz mulheres super magras, loiras, raspadas e "siliconadas". Ao contrário, as postagens em geral trazem mulheres morenas, gordinhas, com marcas de celulite e todas as supostas "imperfeições" que as estrelas pornôs parecem esconder, disfarçar ou eliminar por completo. $\mathrm{O}$ site traz tipos de corpos que desafiam o padrão de beleza hegemônico da indústria pornô e também da indústria midiática em geral.

Em Diário da Putaria, o excesso de visibilidade (dos corpos no quadro em uma afirmação direta do diálogo com o pornográfico) e as pornificações de si são apresentados como elementos essenciais da composição de cada quadro, pois a emulação do repertório associado à imaginação pornográfica, a sexualização e a pornificação do próprio corpo são entendidas como fontes de engajamento do consumo dos corpos e do próprio prazer.

O registro no site é gratuito, bem como acesso ao seu conteúdo que segue uma estrutura de $b \log$, mas onde também é dada ao usuário a possibilidade de adicionar um site pessoal que figura então como link em uma das barras laterais da página inicial. Mais importante, há um espaço para o comércio de sexo explícito: "O escritório da putaria" funciona como uma área de publicidade onde anúncios de serviços sexuais e propostas de encontros sexuais remunerados são feitos.

É marcante no site sua característica colaborativa, em consonância com o cenário diagnosticado por alguns autores, Henry Jenkins entre outros, como cultura participativa. Nesse sentido, o site se configura como um objeto interessante para refletir sobre o estatuto da pornografia amadora, ao mesmo tempo em que esboça uma ideia do uso de elementos do cotidiano e da intimidade como fontes de performance e prazer através da pornificação de si. A lógica da circulação de produtos de representação do sexo que estão presentes no "Diário da Putaria" legitima o que chamamos de um novo ambiente pornográfico, marcado pelo consumo dos corpos, de sexualidade e pelo desejo de se pornificar.

Através de suas características específicas, a construção narrativa dos quadros articula o cenário global da construção colaborativa de identidades baseada em autoapresentação e interação e trocas contínuas entre usuários e consumidores, borrando as fronteiras do consumo, da produção e do comércio do sexo. Nesse sentido, Feona Attwood ao desenvolver alguns apontamentos sobre o que ela chama de "cultura de gosto de sexo de novo" salienta que "o crescimento rápido de novas formas de pornografia online está borrando as fronteiras entre o pornográfico e outras estéticas de produção de imagem, entre formas comerciais e não comerciais de representações do sexo, entre consumo e comunidade e principalmente, borrando as fronteiras entre o sexo como representação e apresentação de si” (ATTWOOD, 2007, p. 454).

É notável em cada imagem do site "Diário da Putaria" uma celebração do ato de se auto-pornificar. Esse elogio imagético e reivindicação ao direito da mulher de se erotizar e sexualizar para o consumo visual alheio também borra as fronteiras entre pornografias alternativas (altporn) $)^{5}$ e pornografias comerciais e tal borramento é

\footnotetext{
${ }^{5}$ Segundo Susanna Paasonen, atualmente, através da internet, surge o que a autora chama de netporn ou altporn, sites que em sua constituição há idéia de uma democratização e diversificação dos discursos sobre o sexo e sobre a sexualidade feminina. Segundo outra estudiosa, Katrien Jacobs, esse tipo de
} 
altamente adensado no campo da internet. Na maioria das imagens postadas site, o ato de enfrentar a câmera e provocar o observador através da pornificação do próprio corpo é colocado como pauta central para pensarmos as construções identitárias e a dimensão do consumo simbólico e sexual articulado pelo site. Um senso de conhecimento cultural compartilhado amarra afetivamente os corpos que se performam e quem os observa e, portanto, reforça de certa maneira as relações comerciais articuladas e incentivadas dentro do próprio site e das postagens.

Além da dimensão do consumo que é adensada através das performances de pornificação de si, o site também se encaixa perfeitamente na idéia desenvolvida por Sergio Messina sobre realcore. Segundo o autor, realcore vem a reboque de uma (re)valorização da realidade como uma marca distinta das imagens e das narrativas, uma marca que intensifica o cotidiano e o aspecto comum e ordinários presentes nos discursos. É importante salientar que o que denominamos realcore não é o mesmo que a estética amadora, embora as duas estéticas compartilhem alguns elementos chaves para sua discursividades, como a valorização do real como efeito e como garantia do realismo presente no que está sendo mostrado aos olhos do espectador. Argumentamos então que tal garantia do real é a fonte de prazer e desejo nas imagens das performances de pornificação de si no site "Diário da Putaria".

\section{PORNÔ AMADOR COMO ESTÉTICA E COMO DISPOSITIVO DE PRAZER}

Antes de nos dedicarmos às análises das imagens buscando entender a construção narrativa do quadro e a articulação entre construções identitárias e consumo presentes nas postagens do site, é necessário definir a diferença entre os dois conceitos centrais para entendermos os objetos de análise em questão, são os conceitos de netporn e pornografia na internet, pois os elementos constitutivos de ambos os conceitos - a abordagem colaborativa, o consumo, a ideia de pertencimento e a construção de comunidades - também são essenciais para lançar luz aos objetivos propostos neste trabalho.

Netporn diz respeito a uma nova forma de produzir conteúdo a partir das mudanças oferecidas pelas novas tecnologias e novas formas de interação propostas em ambientes online. Os sites que se caracterizam por se estabelecerem na lógica da netporn constroem uma ideia de participação e construção de conteúdo colaborativo, onde encontramos a combinação entre consumo e comunidade. Tais sites também constroem uma nova estetização das representações do sexo, aderindo a esses elementos do universo participativo e colaborativo que rege a web 2.0. Em outra direção, temos a definição do conceito de pornografia na internet que se configura mais como uma reciclagem e uma reiteração da velha e heteronormativa pornografia produzida pela indústria pornô tradicional, sem qualquer inovação nas construções narrativas, estéticas ou questionamentos sobre as padronizações que circulam através das imagens da pornografia mainstream (PAASONEN, 2010, p. 298).

pornografia se configuraria como "uma tolerância a tipos de corpo alternativos e a uma sexualidade diversa e queer e também como forma de um ativismo sexual na rede" (JACOBS, 2007). 
Portanto, a partir desses dois conceitos, nosso trabalho tem como objetivo enfatizar as características de produção colaborativa e participativa do site Diário da Putaria, considerando que este se configura no intervalo entre um site de netporn e a simples reprodução da velha pornografia na internet. Procuraremos encontrar maneiras de situar o site em um cenário onde as fronteiras entre a representação sexual, pornificação de si e consumo são completamente borradas e, além disso, onde o consumo é um elemento que lança luz sobre como identidade e comunidade são construídos nesses ambientes online.

Assim, o site "Diário da putaria" se configura como um ótimo exemplo onde os personagens são construídos pela interação entre consumidores e produtores das imagens. $\mathrm{O}$ site e suas postagens são capazes de construir uma relação cada vez mais estreita com a realidade, com a intimidade e o cotidiano de cada mulher que se performa através das postagens. Assim, essas mulheres encontram no site um espaço legítimo para a visibilidade de seus corpos, e é exatamente este link com o "real" que torna o site uma ferramenta de construção de identidade e consolidação de espaço aberto e receptivo para auto-pornificação e as articulações do corpo e do sexo como mercadorias, onde a interação e a troca mútua é elemento essencial para o funcionamento e a dinâmica das postagens e dos comentários.

Argumentamos neste sentido que esta ligação com a realidade presente nas imagens é enfatizada pela estética do pornô amador e a ideia do princípio da dupla evidência e se faz essencial para as trocas permeadas entre produtores e consumidores que circulam no ambiente virtual. Através dessa dupla evidência podemos reconhecer o desejo e as fantasias do outro presente nas imagens como sendo fontes de prazer tanto de quem produz quanto de quem consome os corpos e as sexualidades expostas nas performances. Portanto, vemos que o princípio de máxima visibilidade (para usar uma expressão cunhada por Linda Williams) é central para garantir o status do real e com isso parte da eficácia da experiência estética na construção narrativa de cada postagem.

Aqui também, no entanto, o olhar que encara a câmera fornece, para a narrativa, um outro nível de evidência e link com o "real". A mobilização do desejo através deste link com o "real" é marcada por alguns elementos que consolidam, para usar o conceito de Roland Barthes (1986), seus efeitos de realidade. Podemos argumentar que um elemento importante que marca a influência da realidade é exatamente o olhar que encara a câmera, o corpo que fala e o olhar que encara o sujeito observador/consumidor.

Aliado a isto, a tradição da pornografia como um gênero está claramente associada ao lugar da visibilidade como evidência do real na modernidade que se vê imersa no que Williams vai chamar de frenesi do visível. Assim, a estética do pornô amador adensa o prazer do olhar, pois seu poder de afetação é articulado pela ideia de que as imagens amadoras são mais reais que as imagens da pornografia tradicional. Nesse sentido, Mariana Baltar $(2013,2007,2011)$ defende que o olhar que encara a câmera é geralmente entendido como um indicativo do real presente na imagem.

A marca do amador demonstra como a lógica e a mediação da tecnologia da produção do vídeo tem profundo impacto na construção narrativa do ponto de vista e das práticas de consumo de imagens. Essa marca da estética amadora intensifica as possibilidades de apresentar os aspectos da intimidade e do cotidiano de cada indivíduo. 
O contexto contemporâneo da hipertrofia da intimidade pelo crescente desejo de olhar a intimidade do outro e, acima de tudo, também pelo desejo de ser visto em sua própria intimidade. Dessa forma, salientamos que agora mais do que nunca transformar a intimidade em algo a ser publicizado é hoje uma condição para existir, principalmente no mundo online, onde o que se é define-se pelo o que aparece e o que está visível à flor da pele (SIBILIA, 2008).

É neste lastro teórico e conceitual em torno do amador que a possibilidade de apresentação e pornificação de si ganha cada vez mais espaço no cenário midiático e cultural contemporâneo. A Internet aumenta esta possibilidade de se construir para o olhar do outro, fornecendo uma plataforma perfeita, fácil e acessível, para dar vazão à personalização do desejo do consumo de corpos, identidades e subjetividades e divulgação da intimidade.

Por isso, "Diário da Putaria" pode ser visto como um exemplo do uso da estética amadora para uma pornificação de si, associado também é claro a outras formas de se pornificar como as sex tapes e vídeos caseiros que circulam na internet. Argumentamos então que a dimensão amadora nas postagens no site "Diário da Putaria" reforça a dimensão da pornificação de si como performance e subjetivação e uma construção de uma identidade sexual através das imagens do site. Além disso, a plataforma também envolve um comércio intenso de sexo, consumo e trocas sexuais. $\mathrm{O}$ aspecto comercial não diminui o fator de amador, mas o intensifica.

Nesse sentido, o que está em jogo no "Diário da Putaria" é o que gostaríamos de definir como a construção narrativa do consentimento que se dá através do link com o real e com a intensa relação entre produtores e consumidores das imagens no site, onde o caráter consensual se materializa nas imagens. Argumentamos nesse sentido que a chave interpretativa para pensar as imagens e as questões propostas por este trabalho é analisar o quadro e a pose que constroem uma ideia de consentimento. Como apontaremos nas análises das imagens postadas no site, a construção de si através das fotos e dos vídeos representa muito mais que uma estética amadora, mas uma pornificação de si que mobiliza aspectos de empoderamento do próprio corpo e do próprio prazer que, por sua vez, se legitima e intensifica pela construção narrativa do consentimento presentificado nos quadros e nas poses (uma relação entre sujeito câmera/quadro - espectador/consumidor). Apontamos então que o prazer nessas imagens é uma experiência compartilhada através da pornificação de si.

\section{DIÁRIO DA PUTARIA: ESTÉTICA DO AMADOR, CONSUMO E PORNIFICAÇÃO DE SI}

"Gordinha Baiana" ${ }^{\circ}$ posa para a câmera de frente para o espelho que parece fornecer algumas camadas de segurança para um corpo que não se encaixa nos padrões das estrelas pornôs mais conhecidas. Sem qualquer tratamento de programas digitais (exceto quando seu rosto é desfocado para preservar sua identidade), as fotos são colocadas de forma a construir um tipo peculiar de confissão, centrada no corpo e na sexualidade da mulher que é exposta nas imagens. Embora apresentando uma segurança

\footnotetext{
${ }^{6} \mathrm{http}: / /$ www.diariodaputaria.com/gordinha-baiana/
} 
e um conforto com o próprio corpo em posar para seu próprio espelho, Gordinha Baiana não quer ser reconhecida. Sua identidade sexual é construída em cada imagem através de suas poses que acabam evidenciando suas marcas visíveis, enquanto seu rosto está coberto.

O limiar entre a pornificação de si e a exposição de sua intimidade se materializou através de sua identidade oculta. Ela posa em muitas posições - de quatro, em pé com os pés apoiados em uma cadeira e com as pernas ligeiramente abertas e às vezes completamente abertas. A postagem é contemplada com um bombardeio de comentários, uma quantidade de 20, exaltando sua sexualidade, desejando seu corpo comum, fora do padrão e "gordinho". São comentários que vão desde "você é deliciosa, tão perfeita, só quero ver a sua buceta e gozar a noite toda" até alguns mais instigantes e que sugerem um desdobramento, como: "me envie mais fotos, quero ver mais". Todas as falas construíram uma moldura de exaltação para esta postagem e, além disso, evocam a possibilidade de uma relação offline de consumo do corpo e de outras trocas sexuais (há uma enxurrada de e-mails e de telefones pedindo e propondo encontros).

As fantasias são materializadas através de fragmentos do corpo de Gordinha Baiana (a vagina, a bunda, os seios) e cada fragmento ajuda a compor o prazer e o empoderamento presente no quadro. Embora (e talvez sobretudo por isso mesmo) dona de um corpo fora dos padrões de beleza cristalizados pela mídia hegemônica, corpo gordinho como afirma o título da postagem, Gordinha Baiana veste-se com todos os tipos de fantasia e reafirma seu corpo como desejável e desejado. Lingerie de todas as cores e decotes, fantasias eróticas felinas compõem seu quadro e parecem liberar o corpo das amarras morais culturais contemporâneas; corpo sexualizado, disponível, consumível e empoderado. A pornificação de si de Gordinha Baiana é construída através de seu próprio desejo e também do desejo do outro, e cumpre especialmente a valorização do elemento que é fascínio do imaginário da cultura sexual brasileira: a bunda grande.

O ponto crucial para a nossa análise é exatamente o fato de que, nesta nova lógica de netporn e pornografia na net, os corpos consumidos também são corpos que consomem através da troca mútua e do constante caráter participativo na construção do prazer presente na imagem, permitindo ainda novos intercâmbios. Assim, produtores e consumidores tornam-se apenas um elemento de um jogo complexo em que polos de atuação e passividade não podem mais ser definidos de modo determinado ou determinista.

No reino da netporn, em sites como "Diário da Putaria", mulheres comuns têm a oportunidade de se pornificar e de inserir seus corpos em uma dinâmica de prazer, desejo e fantasias. Embora não totalmente despido de julgamentos morais por parte da sociedade, inserir-se nesta lógica de pornificação de si tem se tornado cada vez mais “aceitável” e, mais importante, prazeroso para as mulheres. É uma mudança cultural que tem sido analisada em teorizações que refletem sobre a construção de uma legitimação do consumo dos corpos e do sexo, bem como o papel do compartilhamento de imagens de corpos ordinários/comuns, inseridos em uma moldura cotidiana, como instância catalisadora do prazer. 
Como apontado por Julie Bradford (2010), para muitas mulheres, o despertar o desejo sexual no outro a partir da erotização e da pornificação do próprio corpo é ação cabal para a construção do seu prazer e desejo. Por outro lado, como já mencionado, Baltar (2013) argumenta que mais que o ato de se expor sexualmente ao olhar público, a pornificação de si é um efeito e instrumento da subjetividade contemporânea que reivindica como desejo e prazer ser cada vez mais visível ao olhar público. Se lermos as imagens em Diário da Putaria, bem como os comentários dos consumidores sobre tais imagens, é possível observar que o prazer evocado nas postagens é uma experiência compartilhada, troca que conduz, algumas vezes, a um intercâmbio de natureza comercial.

A questão que queremos aprofundar neste artigo é como analisar a construção narrativa/discursiva dos quadros do "Diário da Putaria", reconhecendo os problemas relacionados ao pornô amador consensual e à dimensão da pornificação de si que evoca um cenário complexo e paradoxal envolvendo identidade sexual, empoderamento e consumo de corpos sexualizados.

Por isso, é importante chamar a atenção para as marcas narrativas do pornô amador presentes nos quadros. Tais marcas colocam as mulheres tanto como produtoras tanto como donas de seu próprio corpo. No entanto, os mesmos elementos do quadro discursivo que apontam para noções de empoderamento e prazer, também recuperam memórias de olhar heteronormativo e regulamentador do desejo feminino. Há nas postagens de Diário da Putaria uma ambivalência constitutiva do universo da autopornificação: ao mesmo tempo há a evocação de poses, performances e vocabulários que marcaram o pornô mainstream (frequentemente heteronormativo); há também o deslizamento dessa mesma tradição a partir da presença celebrada de corpos fora do padrão (que remete inclusive a distinções de classe e etnia) e da reiteração da mulher como agente do seu corpo, do seu prazer e protagonista da sua pornificação.

A postagem "Fotos Pornô da minha bucetinha"7 reafirmam esse duplo lugar e diálogo com a tradição pornográfica mainstream de modo mais cabal, começando pelo título, e a presença do termo pornô, mas também o que este termo evoca: no caso, closeups da genitália feminina. Interessante também é a descrição da postagem que diz: "Fotos Pornô da minha bucetinha, quero ler os comentários que vou mandar mais, fico excitada e vou me molhar todinha lendo tudo".

Assim, mais uma vez a pornificação de si se alinha à construção do desejo do outro através da exposição do próprio desejo plasmado na imagem do corpo pornificado, erotizado, sexualizado. Trocas de números de telefone, e-mail e sugestões de encontros sexuais também reforçam o caráter amador e o link com o real que é construído pelo quadro.

É necessário, portanto, ir além das dicotomias e trincheiras e reconhecer as relações complexas entre o empoderamento do corpo feminino, consumo do prazer e sujeição dos corpos. Além disso, é importante reconhecer a leitura como um processo interativo. As redes complexas estabelecidas através dos quadros de pornificação de si tornam possíveis articulações diferentes de afetos e práticas de consumo; essa rede tão complexa pode ser vista através da interação pelos comentários, por exemplo.

\footnotetext{
${ }^{7} \mathrm{http}: / /$ www.diariodaputaria.com/fotos-porno-da-minha-bucetinha/
} 
$\mathrm{O}$ quadro e a pose performada nas imagens reforçam o aspecto consensual e amadorístico da imagem, proporcionando uma relação mais estreita com a realidade, que intensificaria a dimensão da partilha do prazer entre produtor e consumidor. Embora o site Diário da Putaria não seja suficiente para romper totalmente com a pornografia mainstream, ele dá provas de que o impacto de tais representações do sexo (pornificação de si e empoderamento) podem adquirir facetas diversas e complexas.

A postagem de "Aninha" dessa rede complexa de participações, pois, embora as legendas das imagens afirmem a mulher como a "narradora" da visualidade das fotos, o que de fato vemos no quadro é um olhar masculino que produz os planos.

Nestas imagens, os corpos femininos são detalhados para o olhar implicadamente masculino, onde a ênfase no prazer masculino é priorizada em cada fotografia. Também é importante perceber que, em cada imagem, o pênis aparece em um incômodo primeiro plano, impondo sua presença acima dos dois corpos femininos.

Por outro lado, a construção narrativa do consentimento é um elemento essencial para ser reconhecido e compreendido na análise dos quadros desta postagem de "Aninha". Neste sentido, sexo consensual, aparentemente sem artifícios - evocando o princípio da dupla evidência do real -, é apresentado nestas fotos a partir da visibilidade da câmera e do uso de planos ponto de vista. As imagens de Aninha colocam-nos dentro de sua "festa de fim de ano", mas não em um olhar íntimo e de auto-apresentação de sua própria sexualidade, mas através de um olhar masculino. Mesmo que o olhar não seja o de Aninha, quando esta olha para a câmera mostrando envolvimento e emoção (enfatizado pela coreografia de olhares entre ela e o suporte da câmera), traz o consentimento como um elemento que ajuda a transmitir seu próprio prazer e, portanto, ajuda a construir o prazer de quem consome a imagem.

A pornografia tradicional trabalha com a lógica da atração, definindo-se com o espetáculo visual de genitálias e números sexuais. No entanto, no caso de Diário da Putaria, a dinâmica é tomada de outra forma, onde a construção da autenticidade da personagem amparada no cotidiano e no comum, e com isso, no estatuto de real, tornam-se importantes elementos para compor o quadro. Assim, cenários de quarto, flashes estourados no espelho, roupas cotidianas (e não apenas as lingeries) ocupam espaço lado a lado com os close-ups na genitália característicos do pornô.

Em algumas publicações, os rostos das mulheres aparecem disfarçados, porém em muitos deles suas identidades estão visíveis, reveladas no rosto enquadrado no autoretrato e pelo olhar que encara a câmera. Nestes, comentários com trocas de e-mails, telefones e pedidos de contato pelo aplicativo WhatsApp são mais intensos. Podemos então argumentar que as postagens que mais possibilitam as trocas e os consumos se dão em quadros cuja interação é mais explícita entre sujeito na imagem e espectador/consumidor e cujos aspectos ligados à vida comum e cotidiana estão mais presentes na imagem, expondo e construindo assim uma sexualidade singularizada através de um auto-retrato pornificado.

\footnotetext{
${ }^{8} \mathrm{http}: / /$ www.diariodaputaria.us2013index.php/?id03-Marcoaninhaemfestadefimdeanonomotel
} 
A ideia de se apropriar da produção e do controle de sua auto-imagem aponta para um empoderamento também do próprio corpo e do próprio prazer. Constroem então através dessas postagens não somente corpos sexualmente desejáveis, mas, acima de tudo, corpos poderosos (e no controle) que se colocam disponíveis para o olhar e o consumo de quem os observa e deseja. Mesmo quando as fotos não são feitas de frente para o espelho, ainda temos imagens sendo produzidas a partir da presença narrativa do consentimento. Argumentamos que encarar a câmera articula tanto o consentimento e a pornificação de si nas imagens, inclusive naquelas que são feitas por terceiros e não pela própria mulher. Nesses casos de imagem feita por um segundo observador, a construção narrativa do consentimento reforça o pacto e a intimidade entre todos os corpos que aparecem na imagem, e é exatamente este pacto que intensifica a prazer compartilhado entre quem produz e quem consome tais imagens.

Em diversas outras postagens podemos também reconhecer toda a retórica do consentimento pelas marcas da pornificação de si na frente do espelho e através de uma construção de um corpo disponível e pronto para o desejo e para o sexo. Mesmo que esses corpos emulem poses retiradas das pornografias mainstream, comumente associadas a uma lógica heteronormativa, elas também mobilizam uma dimensão discursiva de empoderamento ao colocar a mulher como autora da ação que escolhe "oferecer" seu corpo e sua sexualidade para serem admiradas e desejadas. É nesse desejo do outro que está alocado o seu próprio desejo e prazer em se exibir e se pornificar, ativando assim sua sexualidade livre e empoderada. Essa atitude de empoderamento é enfatizada pelos comentários dos consumidores; assim, cada quadro se torna um mais complexo limiar do que uma simples dicotomia entre o corpo feminino colocado como objeto e o empoderamento corporal experienciado pelas mulheres contemporâneas.

$\mathrm{Na}$ visão mais tradicional do debate feminista em torno da pornografia, os homens a consomem e as mulheres são sempre seus objetos. No entanto, tal visão um tanto monolítica que separa as posições de sujeito e objeto do desejo, reiterando de certa forma a visão heteronormativa que coloca o masculino como ativo e o feminino como passivo, vem crescentemente sendo contestada desde meados dos anos $1980^{9}$.

Simon Hardy (1998) escreve que para a mulher se inserir ativamente e não passivamente no discurso do sexo, como um sujeito detento de uma sexualidade empoderada, significaria, para o senso comum, que essa mulher age como uma puta, seu comportamento seria então considerado inadequado. Nesse sentido, o discurso que moraliza o corpo disponível reforça o próprio discurso heteronormativo, superestimando nesse sentido a possibilidade e o direito que a mulher tem de construir e assumir seu próprio desejo e seu próprio prazer sexual ao escolher se objetificar, de se expor e se auto-pornificar para o desejo, o que em certo sentido acaba adensando a discussão ao redor da moralização e padronização negativa na qual a pornografia ganha sustentação na maioria das discussões sobre o tema.

\footnotetext{
${ }^{9}$ Não cabe aqui recontar esse debate, mas, nesse sentido, remeto aos textos de Feona Attwood e aos artigos que compõem o primeiro número do journal Porn Studies, lançado em 2014.
} 
A partir do que foi argumentado até aqui, a postagem de "Sara Gostosa"10 parece ser o exemplo mais concreto e simbólico de construção de um quadro a partir da chave do consentimento, do amador (apresentado durante nossa análise pelos aspectos ordinários, comuns e "reais" do corpo) e da pornificação de si. Com um claro auto conhecimento do próprio corpo e de como apresentá-lo diante da câmera, explorando sempre suas melhores posições, Sara constrói um quadro estritamente amador e que ao mesmo tempo flerta com toda a iconografia pornográfica. Fica claro no seu uso recorrente dos sapatos de salto alto somado ao privilégio dado à sua cintura e seu quadril que Sara pretende delimitar uma zona de prazer para o olhar masculino.

Sara decupa seu próprio corpo como se construísse um plano quadro a quadro muito característico de vídeos pornôs (sendo eles amadores ou não), produzindo closeups de cada elemento de seu corpo que é usado para instigar e construir o desejo e o prazer do consumidor: pernas, coxas, seios, o toque na genitália, pés, ventre, nada escapa ao olhar atento de Sara e sua câmera, sempre mostrando o necessário para construir um corpo pornograficamente desejável e desejante.

Ao esconder seu rosto propositalmente, Sara acaba por compor um elemento interessante no quadro, pois a partir dessa sublimação da face, o corpo ganha vida através da dupla imagem no espelho. Ela cuidadosamente escolhe onde e como ela construirá cada imagem, e quando e como mobilizará o desejo de quem a consome e seu próprio desejo, intensificando seu próprio olhar e a construção narrativa do consentimento.

É importante salientar a força do quadro composto pela postagem de Sara, através da decupagem detalhada de seu corpo, usando close-ups como se estivesse fragmentando seu corpo para o deleite de quem o contempla; tudo é visto e construído através de seu corpo feito visível pela moldura do espelho. A moldura que se faz visível em cada imagem não é enquadrada a esmo ou por acaso, pelo contrário, tal ato demonstra uma consciência da construção do quadro e da própria escolha de enquadramento. Além das poses que denotam a retórica de um pornô heteronormativo (vemos, por exemplo, a partir das poses que privilegiam a bunda grande que se caracteriza por ser um grande fetiche sexual para o público brasileiro), podemos dizer que a marca do amador na postagem de Sara está na luz natural que invade a imagem, em seu tipo corporal e sua clara interação e articulação entre o prazer que é compartilhado entre o corpo que se pornifica e o olhar quer o consome e deseja.

\section{CONSIDERAÇÕES FINAIS}

Para concluir nossa linha argumentativa, afirmamos que o vínculo que é construído entre os espectadores/consumidores e as mulheres que se pornificam nas postagens do site é possível pelo fato de o Diário da Putaria ser construído por conteúdo gerado pelos próprios usuários que acabam por borrar as fronteiras entre corpos consumíveis e corpos que também consomem. Feona Attwood argumenta que tal

\footnotetext{
${ }^{10} \mathrm{http}: / /$ www.diariodaputaria.us/2013/index.php?id=02-Fevereiro/sara
} 
vínculo (entre consumidores e produtor@s) é proporcionado pelo compartilhamento de conteúdo colaborativo em plataformas participativas (2007, p.446).

As imagens compartilhadas em Diário da Putaria salientam a centralidade, no contexto contemporâneo, da pornificação de si como um meio de se auto construir e auto representar nas vitrines da rede. As mulheres contemporâneas articulam tal reivindicação através de construções narrativas de um consentimento de ver e ser vista e, com isso, reivindicam a dimensão prazerosa dessa troca de visibilidades. Como analisado por nós neste artigo, a pose, o quadro que apresenta a interação entre o corpo que se expõe e a câmera e a presença visível do aparato tecnológico na imagem (como pode ser visto nas imagens feitas de frente para o espelho, construindo a partir deste as molduras da decupagem visual do corpo) recuperam tanto a estética amadora como também as marcas de uma imaginação pornográfica. Todos esses elementos entram nos jogos complexos entre poder e prazer articulados nas dinâmicas de visibilidades dos corpos.

\section{REFERÊNCIAS}

ATTWOOD, F. No money shot? Commerce, pornography and new sex taste cultures. In Sexualities, v. 10, n. 4: 441-456, 2007.

. Sexed up: theorizing the sexualization of culture. In Sexualities, v. 9, n. 1: 77-94, 2006.

. Fashion and passion: marketing sex to women. In Sexualities, v. 8, n. 4: 392-406, 2005.

BALTAR, M. Femininas pornificações. In BRAGANÇA, Maurício de; TEDESCO, Marina (org).

Corpos em projeção: gênero e sexualidade no cinema latino-americano. Rio de Janeiro: 7 Letras, 2013.

. Realidade lacrimosa: diálogos entre o universo do documentário e a imaginação

melodramática. 2007. Tese (Doutorado em Comunicação).

. Princípio da dupla evidência - o vídeo amador na interconexão entre pornografia e documentário. In: XII Estudos de Cinema e Audiovisual v.1. São Paulo: Ed. Socine, 2011. BARTHES, Roland. The rustle of language. Berkeley: University of California Press, 1986. BRADFORD, Julie. Rewriting the script: women, pornography and web 2.0. (conference at Postgraduate Research Day at University of Sunderland), 2010.

DENNIS, Kelly. Art/porn. A History of seeing and touching. Oxford/NY, Berg, 2009.

JANCOVICH, Mark. Naked ambitions: pornography, taste and the problem of the middlebrow. In Scope, 2001.

JENKINS, Henry. Convergence culture: where old and new media collide. New York: New York University Press, 2010.

LIPOVETSKY, Gilles. Os tempos hipermodernos. São Paulo: Barcelona, 2004. Sulina, 2009.

; SERROY, Jean. Tela global. Mídias culturais e cinema na era hipermoderna. Porto Alegre:

MARTIN-BARBERO, Jesús. Dos meios às mediações - comunicação, cultura e hegemonia. 2. ed. Rio de Janeiro: EdUFRJ, 2001.

MELENDEZ, F.. Video pornography, visual pleasure and the return of the sublime. In WILLIAMS, Linda (org). Porn Studies. Duke University Press, 2004.

NICHOLS, B.. Pornography, ethnography and the discourses of power. In Representing reality. Bloomington, Indianapolis, Indiana University Press, 1991.

Ideology and the image. Social representation in the cinema e other media. 1981.

PAASONEN, Susanna. Labors of love: netporn web 2.0 and the meanings of amateurism. In: New Media Society, 2010. 
PATTERSON, Zabet. Going on-line: consuming pornography in the digital era. In WILLIAMS, Linda (org). Porn Studies. Duke University Press, 2004.

WILLIAMS, L. Hard Core. Power, pleasure and the frenzy of the visible. 1999.

SÁNCHEZ-BIOSCA, Vincente. Una cultura de la fragmentación. Pastiche, relato y cuerpo en El cine y la televisión. Valencia: Filmoteca de la Generalitat Valenciana, 1995.

SARTI, Cynthia Andersen. O feminismo brasileiro desde os anos 1970: revisitando uma trajetória. In

Revista Estudos Feministas, Florianópolis, v. 12, n. 2, maio-agosto/2004.

WINSTON, Brian. Claiming the real. The griersonian documentary and its legitimations. London: BFI Publishing, 1995.

Recebido em 20/09/2014. Aprovado em 24/11/2014.

Title: Selfpornification in Diário da Putaria

Abstract: This article aims to reflect about the female bodies that populate the multiple online screens in the contemporary pornography context, arguing that these images mobilize new discursive constructions of sexuality and pleasure. Accordingly, we intend to analyze the Brazilian site "Diário da Putaria" with the aim to investigate specific aspects of the so-called netporn, it's political, cultural and imagery dimension. From this issue, we propose to think the interconnections between the amateur porn and what some thinkers of the area have reflected as "self-pornification". Therefore, we propose to understand the disputes present in these images and, with it, investigate issues related to the production and consumption logic of pornography images relating the ideas of self-pornification, empowerment and pleasure.

Keyword: Pornograph. Selfpornification. Gender. Amateur. Web 2.0. 